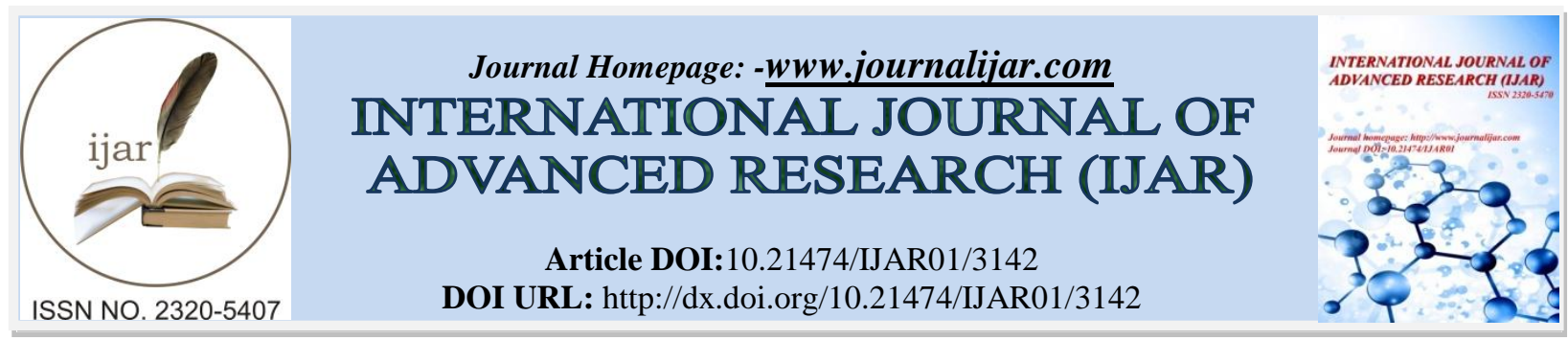

RESEARCH ARTICLE

\title{
RELATIONSHIP BETWEEN APPENDICITIS AND LIFESTYLE; DIETARY AND HYGIENE IN SAUDI ARABIA.
}

\begin{abstract}
*Ibrahim Ahmed Alzahrani, Saad Attiah Al-Sehli, Ahmed Ali Alsharif, Rayyan Ahmad Alqurayyan, Reem Fahad Alshenaifi, Amal Mohammed Ayoub Omar, Alaa Ahmed Ibrahim Saif, Mather Jafar Alabduljabbar, Morshed Ali Mohammed Alsawidan ,Esra Ali Alhwsawi and Ali Salem Alhamidah.
\end{abstract}

\section{Manuscript Info}

Manuscript History

Received: 06 December 2016

Final Accepted: 14 January 2017

Published: February 2017

\section{Abstract}

Acute appendicitis (AA) is considered as one of the most common causes of surgical emergencies worldwide (1). The gold standard treatment for AA is Appendectomy (2). About 6\% of the population during their lifetime, will suffer from acute appendicitis $(3,4)$. Males suffer from acute appendicitis than females $(8.6 \%$ and $6.7 \%$ respectively) $(5,6)$. Acute appendicitis rarely causing death; with a mortality rate ranges from zero up to $2.4 \%$ (8). However, more attention has been directed for early diagnosis and intervention. A crosssectional study was conducted to assess the relationship between appendicitis and lifestyle; dietary and hygiene in Saudi Arabia. This study showed defects in Dietary life style for acute appendicitis patients including, low consumption of water, a significant decrease in the containment of fiber at the usual food.

Copy Right, IJAR, 2017,. All rights reserved.

\section{Introduction:-}

Acute appendicitis (AA) is considered as one of the most common causes of surgical emergencies worldwide (1). The gold standard treatment for AA is Appendectomy (2). About $6 \%$ of the population during their lifetime, will suffer from acute appendicitis $(3,4)$. Males suffer from acute appendicitis than females ( $8.6 \%$ and $6.7 \%$ respectively) $(5,6)$. Acute appendicitis rarely causing death; with a mortality rate ranges from zero up to $2.4 \%$ (8). However, more attention has been directed for early diagnosis and intervention.

Appendicitis secondary to hyperplasia of the appendiceal lymphoid follicles as a result of a bacterial or viral infection is the most common etiology of appendicitis in children. While the appendicitis as a result of fecal material or fecalith occurs more commonly in adults $(14,15)$. There are different factors are responsible for acute appendicitis perforation in different age groups and this can be explained by the difference in immune status and appendicitis aetiologies (8). The industrialized nations have registered increased happening of appendicitis, constipation, diverticulitis, irritable bowel syndrome (IBS), and colon cancer (16).

In the AA management, the key for successful management is early diagnosis and prompt surgical intervention (9). The late diagnoses of could lead to gangrene and perforation. The perforation occur within $8-24$ hours in children, while it occur within 36 hours in young children and adolescents (8). Causes of delayed diagnosis include; home remedies, homeopathic, local doctors, quacks, and medical practitioners, (8). 
The most common symptom of AA is abdominal pain. According to the National Institutes of Health, the pain begins typically near the belly button, and then it moves to the abdomen lower right side, usually along a period of $(12-24)$ hours. The pain gets worse often if the patient moves around, coughs, takes deep breaths, or sneezes (10). There are many other diseases of gastrointestinal tract which mimic AA making it difficult in diagnosis. (11,12). Diagnosis difficulties arise in females at reproductive age, very young, and elderly patients because they are more possible to have an atypical presentation. They also have many other conditions may mimic acute appendicitis (13).

In spite of the fact that the acute appendicitis etiology and many etiologic factors have been subject of discussion and speculation, multiple factors are probably included in the disease pathophysiology are still unknown. These include non-specific factors, as well as bacterial, fungal, and viral infections and dietary regimens with low fiber (16). Therefore this study was conducted to assess the relationship between appendicitis and lifestyle ; dietary and hygiene in Saudi Arabia .

\section{Objectives:-}

- To describe the characteristics f the patient with appendicitis.

- $\quad$ To determine the relationship between appendicitis and life style (dietary and hygiene ).

- To determine the relationship between appendicitis and medical and surgical problems.

\section{Subjects and Methods:-}

A cross-sectional study was conducted to assess the relationship between appendicitis and lifestyle ; dietary and hygiene in Saudi Arabia . During the period from 1, August 2016 to 8, September 2016, in the following hospitals; King Fahad university hospital in Al- khobar, Dammam central hospital, Imam Abdurrahman Bin Faisal hospital ( Dammam National Guard), King Fahad specialist hospital in Dammam, king Fahad medical military complex, king Fahad central Hospital in Jizan, Abu Areash General Hospital, king Fahad general hospital in Medina, National Guard hospital Medina, National Guard hospital in Jeddah, Alansar hospital in Medina, Al-rrass general hospitals in Qassium, Prince Sultan Armed force hospital in Medina, Qatif central hospital in Qatif, Dammam medical complex, King Khalid hospital, Hail general hospital, King Fahad medical city Qassium, king Fahad hospital in AlHassa, Bin Jalawi Hospital in AlHassa, Dammam medical center, King Fahad Medical City, king Faisal specialist hospital \& research center, and King Abdul-Aziz hospital in Jeddah.

Data were collected by data collectors by means of personal interview with the sampled patients, after obtaining their consents and hospital approval to participate in the study, using a predesigned questionnaire. Each patient was interviewed separately, and confidentiality was assured. It has been to maintain the confidentiality of the information for each patient. The questionnaire designed by researchers, its contains four sections. The first section is about socio-demographic characteristics which includes Gender, Age (years), Marital status, Place of residence, Weight $(\mathrm{kg})$, and Length $(\mathrm{cm})$. Second section includes the questions regarding dietary life style. While third section to assessthe hygiene life style. And Fourth section is including questions about chronic medical and surgical problems. The study included (923) patients whose diagnosed with appendicitis postoperatively and were attending certain hospitals in Saudi Arabia. The patients more 60 years old or less than 12 years were excluded. Collected data were coded and analyzed using statistical analysis program (SPSS v.22), in addition to using of necessary statistical methods to achieve the objectives of the study including frequencies, percentages, graphs, and chi-square test.

\section{Results:-}

Table (1) shows the appendicitis patients distribution according to their personal data, as $59.4 \%$ of them were males, while $40.6 \%$ of them were females.

Their ages were distributed according to the following age groups, 39.2\% of them were between (18-25) years old, $25.9 \%$ of them were less than (18) years old, while $22.1 \%$ of them were between $(26-35)$ years old.

And their distribution according to their marital status; most of them were not married with a percentage of $64.4 \%$, while $35.6 \%$ of them were married.

And according to their weights; $41.4 \%$ of them had weights less than (60) K.g, $29.3 \%$ of their weights were in the range (61- 75) k.g, $20.1 \%$ of their weights were between (76-90) k.g, and $9.3 \%$ of their weights were more than (90) k.g. 
And finally their distribution according to their length; $35 \%$ of their lengths were between (161- 170) cm, 34.6\% of them were between $(150-160) \mathrm{cm}$, and $20.5 \%$ of them were between $(171-180) \mathrm{cm}$.

Table 1:- Personal data for the patients $(\mathrm{n}=916)$.

\begin{tabular}{|c|c|c|c|c|}
\hline \multicolumn{2}{|c|}{ Variable } & No. & $\%$ & P-value \\
\hline \multirow[t]{2}{*}{ Gender } & Male & 544 & 59.4 & \multirow[t]{2}{*}{$0.00 * *$} \\
\hline & Female & 372 & 40.6 & \\
\hline \multirow[t]{5}{*}{ Age (years) } & Less than 18 & 237 & 25.9 & \multirow[t]{5}{*}{$0.00 * *$} \\
\hline & $18-25$ & 359 & 39.2 & \\
\hline & $26-35$ & 202 & 22.1 & \\
\hline & $36-45$ & 75 & 8.2 & \\
\hline & More than 45 & 43 & 4.7 & \\
\hline \multirow[t]{2}{*}{ Marital status } & Single & 590 & 64.4 & \multirow[t]{2}{*}{$0.00 * *$} \\
\hline & Married & 326 & 35.6 & \\
\hline \multirow[t]{6}{*}{ Place of residence } & Eastern Region & 255 & 27.8 & \multirow[t]{6}{*}{$0.00 * *$} \\
\hline & Western Region & 243 & 26.5 & \\
\hline & North Region & 36 & 3.9 & \\
\hline & Southern Region & 130 & 14.2 & \\
\hline & Central Region & 215 & 23.5 & \\
\hline & Outside the kingdom & 37 & 4.0 & \\
\hline \multirow[t]{4}{*}{ Weight $(\mathrm{kg})$} & Less than 60 & 379 & 41.4 & \multirow[t]{4}{*}{$0.00 * *$} \\
\hline & $61-75$ & 268 & 29.3 & \\
\hline & $76-90$ & 184 & 20.1 & \\
\hline & More than 90 & 85 & 9.3 & \\
\hline \multirow[t]{5}{*}{ Length $(\mathrm{cm})$} & Less than 150 & 53 & 5.8 & \multirow[t]{5}{*}{$0.00 * *$} \\
\hline & $150-160$ & 317 & 34.6 & \\
\hline & $161-170$ & 321 & 35.0 & \\
\hline & $171-180$ & 188 & 20.5 & \\
\hline & More than 180 & 37 & 4.0 & \\
\hline
\end{tabular}

**Chi Square test - Significant at the 0.01 level

Table 2:- Dietary life style

\begin{tabular}{|c|c|c|c|}
\hline \multicolumn{2}{|c|}{ Question } & No. & $\%$ \\
\hline \multirow[t]{4}{*}{ Daily water consuming } & cup, small bottle & 141 & 15.4 \\
\hline & Less than 6 cups & 498 & 54.4 \\
\hline & 6- 12 cups & 243 & 26.5 \\
\hline & More than 12 & 34 & 3.7 \\
\hline \multicolumn{2}{|c|}{ Total } & 916 & 100.0 \\
\hline \multirow{4}{*}{$\begin{array}{l}\text { How many times do you eat } \\
\text { vegetables daily? }\end{array}$} & Once & 756 & 82.5 \\
\hline & Twice & 122 & 13.3 \\
\hline & Three & 26 & 2.8 \\
\hline & More & 12 & 1.3 \\
\hline \multicolumn{2}{|c|}{ Total } & 916 & 100.0 \\
\hline \multirow{4}{*}{$\begin{array}{l}\text { How many times do you eat fruits } \\
\text { daily? }\end{array}$} & Once & 800 & 87.3 \\
\hline & Twice & 91 & 9.9 \\
\hline & Three & 21 & 2.3 \\
\hline & More & 4 & 0.4 \\
\hline \multicolumn{2}{|c|}{ Total } & 916 & 100.0 \\
\hline \multirow{4}{*}{$\begin{array}{l}\text { How many times do you eat grains } \\
\text { daily? }\end{array}$} & Once & 736 & 80.3 \\
\hline & Twice & 143 & 15.6 \\
\hline & Three & 26 & 2.8 \\
\hline & More & 11 & 1.2 \\
\hline \multicolumn{2}{|c|}{ Total } & 916 & 100.0 \\
\hline Do you prefer adding chili to your & Every me & 199 & 21.7 \\
\hline
\end{tabular}




\begin{tabular}{|c|c|c|c|}
\hline \multirow[t]{2}{*}{ food? } & Sometimes & 384 & 41.9 \\
\hline & No & 333 & 36.4 \\
\hline \multicolumn{2}{|c|}{ Total } & 916 & 100.0 \\
\hline \multirow{2}{*}{$\begin{array}{c}\text { Do you have particular food } \\
\text { system? }\end{array}$} & Yes & 55 & 6.0 \\
\hline & No & 861 & 94.0 \\
\hline \multicolumn{2}{|c|}{ Total } & 916 & 100.0 \\
\hline \multirow{2}{*}{$\begin{array}{c}\text { Do you eat in bronchial } \\
\text { restaurants? }\end{array}$} & Yes & 669 & 73.0 \\
\hline & No & 247 & 27.0 \\
\hline \multicolumn{2}{|c|}{ Total } & 916 & 100.0 \\
\hline \multirow{2}{*}{$\begin{array}{l}\text { Do you eat in fast food } \\
\text { restaurants? }\end{array}$} & Yes & 808 & 88.2 \\
\hline & No & 108 & 11.8 \\
\hline \multicolumn{2}{|c|}{ Total } & 916 & 100.0 \\
\hline
\end{tabular}

We conclude from the above table that $54.4 \%$ of Appendicitis patients consuming less than (6) cups of water a day, and $82.5 \%$ of them eat vegetables just once a day, and $87.3 \%$ of them were consuming fruits once a day, and $80.3 \%$ of them eat grains once a day.

As we conclude that $21.7 \%$ of Appendicitis patients preferred adding hot sauce to all of their meals, while $41.9 \%$ of them prefer that for some of their meals, and $36.4 \%$ of them didn't prefer to add hot sauce to their meals.

And also conclude from the above table that $94 \%$ of Appendicitis patients didn't follow specific food system, and $73 \%$ of them eat from bronchial restaurants, and $88.2 \%$ of them eat from fast food restaurants.

Table 3:- Hygiene life style.

\begin{tabular}{|c|c|c|c|}
\hline \multicolumn{2}{|c|}{ Question } & $\mathrm{No}$ & $\%$ \\
\hline \multirow{3}{*}{$\begin{array}{l}\text { Do you wash your hands before } \\
\text { eating? }\end{array}$} & Yes & 461 & 50.3 \\
\hline & No & 83 & 9.1 \\
\hline & Sometimes & 372 & 40.6 \\
\hline \multicolumn{2}{|l|}{ Total } & 916 & 100.0 \\
\hline \multirow[t]{3}{*}{ Do you eat foods from peddlers? } & Yes & 224 & 24.5 \\
\hline & No & 313 & 34.2 \\
\hline & Sometimes & 379 & 41.4 \\
\hline \multicolumn{2}{|l|}{ Total } & 916 & 100.0 \\
\hline \multirow{2}{*}{$\begin{array}{l}\text { Do you use bathrooms too much ( } \\
\text { in public places or in crowded } \\
\text { home)? }\end{array}$} & Yes & 424 & 46.3 \\
\hline & No & 492 & 53.7 \\
\hline \multicolumn{2}{|l|}{ Total } & 916 & 100.0 \\
\hline \multirow{2}{*}{$\begin{array}{l}\text { What type of bathrooms do you } \\
\text { use? }\end{array}$} & Old ones (Arabian) & 427 & 46.6 \\
\hline & Chair bathrooms & 489 & 53.4 \\
\hline \multicolumn{2}{|l|}{ Total } & 916 & 100.0 \\
\hline
\end{tabular}

We conclude from the above table that $50.3 \%$ of Appendicitis patients they wash their hands before each meal, and $24.5 \%$ of appendicitis patients eat foods from peddlers. and $46.3 \%$ of them always use public bathrooms or crowded home bathrooms, and $53.4 \%$ of them use chair bathrooms, while $46.6 \%$ of them used old ones (Arabian).

Table 4:- Chronic medical and surgical problems.

\begin{tabular}{|c|c|c|}
\hline Question & $\begin{array}{c}\text { Yes } \\
\text { No. }(\%)\end{array}$ & $\begin{array}{c}\text { No } \\
\text { No. }(\%)\end{array}$ \\
\hline Do you suffer from chronic constipation? & $161(17.6 \%)$ & $755(82.4 \%)$ \\
\hline \multicolumn{3}{|c|}{ Did you diagnosed for any of this disease before feeling the pain? } \\
\hline - $\quad$ Chronic inflammatory bowel disease & $5(0.5 \%)$ & $911(99.5 \%)$ \\
\hline - Inflammation of the respiratory tract & $54(5.9 \%)$ & $862(94.1 \%)$ \\
\hline - $\quad$ Parasitic infection in the digestive tract & $40(4.4 \%)$ & $876(95.6 \%)$ \\
\hline - Colon tumor & $8(0.9 \%)$ & $908(99.1 \%)$ \\
\hline - $\quad$ Appendix tumor & $32(3.5 \%)$ & $884(96.5 \%)$ \\
\hline - $\quad$ Stomach injury(accident, beating or stap) & $29(3.2 \%)$ & $887(96.8 \%)$ \\
\hline A surgery in the right side abdomen & $44(4.8 \%)$ & $872(95.2 \%)$ \\
\hline
\end{tabular}


We conclude from the above table that $82.4 \%$ of Appendicitis patients didn't suffer constipation, and the $9 \%$ of them suffer from inflammation of the respiratory tract, and $4.8 \%$ of them had already conduct surgery in the right side abdomen, also $4.4 \%$ of Appendicitis patients suffered from parasitic infection in the digestive tract.

Also we conclude from the table that $3.5 \%$ of Appendicitis patients suffered from appendix tumor, and $3.2 \%$ of them suffered from abdomen injury, and $0.9 \%$ of them suffered from colon tumor, finally $0.5 \%$ of them suffered from chronic inflammatory bowel disease.

\section{Discussion:-}

Acute appendicitis continues to be the commonest cause of surgical abdominal emergency (1). There are different factors are responsible for acute appendicitis perforation in different age groups (8). These include non-specific factors, as well as bacterial, fungal, and viral infections and dietary regimens with low fiber (16). Consequently this study aimed to to assess the relationship between appendicitis and lifestyle ; dietary and hygiene in Saudi Arabia .

In a report for World Health Organization, it was estimated that adult females needed of water 2.2L/day and males $2.5 \mathrm{~L} /$ day (17). Equivalent to 8-8.5 cups of water daily, but in our study more than half of appendicitis patients consume less than 6 cups of water daily, and the most of them follow this rate of water consumption more than 2 months ago. This low consumption of water contributes at causing the slow bowel movement followed by constipation and thus lead to appendicitis. Case study reported that, Low water intake may also be a causative influence of appendicitis (18).

Concerning fiber consumption, results of this study showed a significant decrease in the containment of fiber at the usual food for acute appendicitis patients. Also there was a significant proportion of acute appendicitis patientsweren't going to defecate daily. Our finding compatible with Imanieh et al., found that a high rate of constipation in patients with lower fiber intake, (16). which is consistent with the hypothesis indicating the role of dietary fibers in lowering the incidence of appendicitis. Whereas the water content of dietary fiber is three times its density(16), it forms softer and heavier stools with a larger volume and reduced passage time (19), it also increase mucus production by the intestinal mucosa (20), and to decrease contraction frequency of the cecal circular muscle (21). Thus lowering the probability of contracting appendicitis as compared to stools with lesser fiber (16). Volz was the first to describe the relationship between the presence of fecalith and inflammation of the appendix. The belief that luminal obstruction is an important factor in the pathogenesis of acute appendicitis is based on the finding of fecalith in many patients with advanced disease (22).

Most of our appendicitis patients eat grains only one time daily, Cummings and colleagues 14 found bran to cause the greatest increase in fecal weight of the dietary fibers they studied (23).

A beneficial role of spices has been reported in obesity, cardiovascular and gastrointestinal conditions, various cancers, neurogenic bladder, and dermatologic conditions (24), but spices also exhibit antibacterial activity and affect gut microbiota populations (25). This means that the spices have both beneficial and harmful effects on the digestive system. In the present study most of acute appendicitis patients preferred having spicy meals, But not on a daily basis, or continuously.

Also the most of our participants consume food restaurants, whether bronchial restaurants or fast food. It is known that food restaurants contains high levels of fat and low in fiber and this in turn hinders the process of digestion and aggravate constipation and thus increases the likelihood of suffering from acute appendicitis.

The causes of appendicitis have been hypothesized to be multifactorial, with diet considered to be a major predisposing factor and viral agents, bacteria, or environmental pollutants playing a secondary or precipitating role (26). In our study the participants showed moderate Hygiene life style. It is natural that this moderate Hygiene life style increase the chances of bacteria and viruses infection, which in turn increase the chances of acute appendicitis. Contrary to previous statements there is no evidence that disease rates were greatly influenced by the dietary changes in the second world war. It is concluded that dietary changes do not explain the time trends in appendicitis and that the epidemiology of the disease is more readily explained by a primarily infectious aetiology (27).

Knowing that appendicitis is difficult to diagnose in the steroid dependent patients who are taking steroids for other illnesses like Chronic inflammatory bowel disease and Inflammation of the respiratory tract due to anti- 
inflammatory and immunosuppressive effects of steroids. Also steroids Inhibits pain so it hinder the diagnosis of acute appendicitis. The most of our participants didn't suffer from Chronic medical and surgical problems.

\section{Conclusion:-}

This study showed defects in Dietary life style for acute appendicitis patients including, low consumption of water, a significant decrease in the containment of fiber at the usual food. This lead to a significant proportion of acute appendicitis patients weren't going to defecate daily. Also the acute appendicitis patients showed moderate hygiene life style, this could contributes in increasing the probability of appendicitis patients. There was low prevalence of chronic medical and surgical problems among acute appendicitis patients including.

\section{Recommendation:-}

- Work on community awareness of risk factors that increase the chances of acute appendicitis.

- Guidance of children in schools on healthy diet and the importance of drinking water and personal hygiene because they are the most vulnerable to appendicitis.

- $\quad$ Adult females need 2.2L of water per day while males need $2.5 \mathrm{~L}$ of water per day.

- The daily diet should contain a sufficient amount of fiber.

- Work to avoid constipation and treated as soon as it happens.

- Maintaining personal hygiene as much as possible.

\section{Acknowledgements: -}

The authors would like to thank all the students and interns who participated in this study especially Mohammad Mustafa Aljafarfor their extraordinary effort as a data collectors.

\section{References:-}

1. Douglas, Charles D., et al. "Randomised controlled trial of ultrasonography in diagnosis of acute appendicitis, incorporating the Alvarado score." Bmj321.7266 (2000): 919.

2. Schwartz SI, Brunicardi FC. Schwartz's Principles of Surgery. 9thed. New York: McGraw-Hill, Medical Pub. Division; 2010. pp. 1073-1082.

3. Cuschieri, A. "The small intestine and vermiform appendix." Essential surgical practice 3 (1995): 1325-8.

4. Kanumba, Emmanuel S., et al. "Modified Alvarado scoring system as a diagnostic tool for acute appendicitis at Bugando Medical Centre, Mwanza, Tanzania." BMC surgery 11.1 (2011): 1.

5. Von Titte, Sigmond N., Charles J. McCabe, and Leslie W. Ottinger. "Delayed appendectomy for appendicitis: causes and consequences." The American journal of emergency medicine 14.7 (1996): 620-622.

6. England, R. J., and D. C. G. Crabbe. "Delayed diagnosis of appendicitis in children treated with antibiotics." Pediatric surgery international 22.6 (2006): 541-545.

7. Shawana, et al. "CAUSES OF DELAYED PRESENTATION OF ACUTE APPENDICITIS AND ITS IMPACT ON MORBIDITY AND MORTALITY." Journal of Ayub Medical College Abbottabad 27.3 (2015): 620-623.

8. Ohmann, Christian, Qin Yang, and Claus Franke. "Diagnostic scores for acute appendicitis. Abdominal Pain Study Group." The European journal of surgery= Actachirurgica 161.4 (1995): 273-281.

9. Bundy, David G., et al. "Does this child have appendicitis?." Jama 298.4 (2007): 438-451.

10. Wong, Kenneth KY, Tammy WY Cheung, and Paul KH Tam. "Diagnosing acute appendicitis: are we overusing radiologic investigations?." Journal of pediatric surgery 43.12 (2008): 2239-2241.

11. Karia, Jagdish B., et al. "Utility of Alvarado score in diagnosing acute appendicitis in children: a cross sectional study." National Journal of Medical Research 4.2 (2014): 125-127

12. Gilmore, O. J. A., et al. "Appendicitis and mimicking conditions: a prospective study." The Lancet 306.7932 (1975): 421-424.

13. Ghahramani, Leila, et al. "Acute Appendicitis as Complication of Colon Transit Time Study; A Case Report." Middle East journal of digestive diseases 7 (2015): 185.

14. Maa J, Kirkwood KS. The Appendix. In) Townsend CM Jr. Beauchamp RD (eds), Sabiston Textbook of Surgery (18th ed). Sauners; 2008, chap.49.

15. Imanieh, M. H., et al. "Bowel movement patterns in children with acute appendicitis." Iranian Red Crescent Medical Journal 2007.2 (2007): 86-92. 
16. Bartram, Howard G., and Guy Howard. "Domestic water quantity: Service level and health." Geneva: WHO (2003).

17. Nelson, M., D. J. Barker, and P. D. Winter. "Dietary fibre and acute appendicitis: a case-control study." Human nutrition. Applied nutrition 38.2 (1984): 126-131.

18. Payler, D. K. "Food fibre and bowel behaviour." The Lancet 301.7816 (1973): 1394.

19. Cassidy, Marie M., et al. "Effect of chronic intake of dietary fibers on the ultrastructural topography of rat jejunum and colon: a scanning electron microscopy study." The American journal of clinical nutrition 34.2 (1981): 218-228.

20. Brodribb, John, et al. "Influence of dietary fiber on transit time, fecal composition, and myoelectrical activity of the primate right colon." Digestive diseases and sciences 25.4 (1980): 260-266.

21. Arnbjörnsson, Einar, and StigBengmark. "Role of obstruction in the pathogenesis of acute appendicitis." The American journal of surgery 147.3 (1984): 390-392.

22. Cummings, J. H., et al. "Colonic response to dietary fibre from carrot, cabbage, apple, bran, and guar gum." The Lancet 311.8054 (1978): 5-9.

23. Sharma, Surinder Kumar, Amarjit Singh Vij, and Mohit Sharma. "Mechanisms and clinical uses of capsaicin." European journal of pharmacology 720.1 (2013): 55-62.

24. Qin, Junjie, et al. "A metagenome-wide association study of gut microbiota in type 2 diabetes." Nature 490.7418 (2012): 55-60.

25. Martin, Deborah L., and Tracy L. Gustafson. "A cluster of true appendicitis cases." The American journal of surgery 150.5 (1985): 554-557.

26. Barker, D. J. "Acute appendicitis and dietary fibre: an alternative hypothesis." Br Med J (Clin Res Ed) 290.6475 (1985): 1125-1127. 